\title{
O MATERIALISMO HISTÓRICO REVISADO. HABERMAS APÓS MARX
}

\section{EL MATERIALISMO HISTÓRICO REVISADO. HABERMAS DESPUÉS DE MARX}

\author{
REVISED HISTORICAL MATERIALISM. \\ HABERMAS AFTER MARX
}

Manoel Ribeiro de Moraes Junior*

Recebido: 01/2017

Aprovado: 05/2017

\begin{abstract}
Resumo: Materialismo Histórico é revisado a partir de uma radicalização da interdisciplinaridade da Escola de Frankfurt. Habermas repensa o materialismo histórico a partir de uma leitura quase transcendental da linguagem e assim interpondo trabalho e interação como condições elementares no processo de socialização.

Palavras-Chave: Teoria e práxis, Materialismo, Teoria da Socialização Linguística, Trabalho.

Resumen: El materialismo histórico se revisa desde una radicalización de la interdisciplinariedad de la Escuela de Frankfurt. Habermas se replantea el materialismo histórico de una lectura casi trascendental de la lengua y la interposición de este modo el trabajo y la interacción como las condiciones básicas en el proceso de socialización.

Palabras chave: Teoría y praxis, Materialismo, Teoría de la Socialización Lingüística,

Trabajo

Abstract: Historical Materialism is reviewed from a radicalization of interdisciplinarity of the Frankfurt School. Habermas rethinks historical materialism from an almost transcendental reading of language and thus interposing work and interaction as basic conditions in the socialization process.
\end{abstract}

Keywords: Theory and practice, Materialism, Socialization Theory of Linguistics, Work.

\section{Introdução}

A história, evolução ou desenvolvimento social são temas presentes nos pensadores da Escola de Frankfurt. Nas obras de Jürgen Habermas, tais temas estão vinculados às questões da transição das sociedades tradicionais para a modernidade, da gênese do capitalismo moderno e da dinâmica de uma sociedade mundial globalizada. Para tanto, Habermas se vê obrigado a lança mão de duas teorias complementares - a saber, o desenvolvimento das competências individuais e a lógica do desenvolvimento social -, através das quais pretende dar conta do fenômeno da racionalização das sociedades modernas.

Concorda com a ideia de que a evolução da compreensão do mundo se faz a partir das estruturas universais de racionalidade, o que significa que essa

\footnotetext{
* Docente do Programa de Pós-Graduação em Ciências da Religião - UEPA. Docente das Licenciaturas em Filosofia e Ciências da Religião - UEPA. Graduado em Filosofia (UERJ). Graduado em Teologia (STBSB). Mestre em Filosofia (UERJ). Doutor em Ciências da Religião (UMESP). Estágio de PósDoutorado em Filosofia (UERJ). Estágio de Pós-Doutorado em Filosofia (CeSoR-EHESS).

Problemata: R. Intern. Fil. V. 8. n. 2 (2017), p. 203-218 ISSN 2236-8612 doi:http://dx.doi.org/10.7443/problemata.v8i2.32453
} 
compreensão está apoiada em níveis crescentes - embora não necessários - de exigências formais em suas formulações explicativas e em suas respectivas justificações (KESSELRING, 1999, p. 75). Entretanto, de forma malograda, a modernização ocidental apoiou-se em aspectos unilaterais de uma orientação cognitivo-instrumental. Por outro lado, se é verdade que a racionalização conduz progressivamente a uma tomada de posição formal em relação aos três mundos, isto não significa que ela esteja concernida com a orientação exclusiva de um paradigma fincado na esfera da ação instrumental.

Os conceitos de razão formal e razão técnico-instrumental não são sinônimos. Cair neste erro, que leva a um reducionismo pessimista, é perder a visão global da razão e de seus usos legítimos. Sendo assim, a experiência negativa do processo de racionalização só é criticável tendo em vista a hipertrofia de um uso objetivante às expensas dos demais.

\section{Elementos do Processo da Socialização}

Habermas entende ser possível reconstruir a gênese universal da competência interativa dos sujeitos socializados, seguindo a tradição de pesquisa proveniente de Chomsky e Piaget, com seus respectivos modelos de análise das estruturas da competência lingüística e da evolução da competência cognitiva. Uma tal investigação parte da idéia de que "possa provar a existência de qualificações básicas anexas às participações em sistemas de interação, à solução de problemas interpessoais e à aprendizagem no ámbito comunicativamente acessível de uma realidade simbolicamente preestruturada como é a interativa. Contudo, cada uma dessas dimensões resguarda uma série de estruturas lógico-evolutivas similares, tornando possível a exposição das competências de modo sistemático, a fim de se esclarecer o desenvolvimento da identidade no contexto intersubjetivo. A partir de Piaget, Habermas procura expor a gênese dessas estruturas universais das capacidades como conseqüência de um enfrentamento entre o sujeito e a realidade que o circunda (a natureza, a linguagem e a sociedade). Destarte, o processo de formação da identidade pode ser entendido como um processo de aprendizagem que torna 0 sujeito capaz de conhecimento, de linguagem e de ação. O desenvolvimento do eu, colocado numa perspectiva além das abordagens solipsistas, é tomado a partir de estruturas "quase-transcendentais" que permitem pensar o indivíduo dentro de um espaço intersubjetivo. A concretização da identidade, lingüisticamente mediada, passa a assegurar tanto a individualidade propriamente dita quanto a intersubjetividade do mundo vivido em que ela se forma. Numa palavra, a formação da identidade se realiza segundo uma lógica 
evolutiva complementar ao desenvolvimento cognitivo, lingüístico e interativo (HABERMAS, 1989, p. 166).

A identidade do eu se explica, portanto, a partir da experiência que Habermas denomina de enfrentamento, responsável pela formação das competências. Ela pode ser entendida como um fenômeno de encontro ativo entre a natureza interna (consciência pessoal) com uma realidade diferenciada (natureza, sociedade e linguagem). Por enfrentamento deve-se entender o momento em que o indivíduo, na sua formação, realiza um intercâmbio integrativo com a realidade que o circunda: com a natureza externa, que o indivíduo percebe e manipula de um modo objetivante, dá-se o momento em que se desenvolve a competência cognitiva; com a realidade pré-científica da linguagem, que se apresenta como mecanismo de manifestações e emissões comunicativas, tem-se o momento em que se desenvolve a competência lingüística; e, enfim, com a sociedade, enquanto realidade simbolicamente préestruturada na qual os sujeitos agem cooperativamente, desenvolve-se a competência interativa de sujeitos socializados pela comunicação. A natureza surge diante da subjetividade como algo que requer objetividade das percepções; a sociedade, cujas instituições e valores são regidos por normas, faz com que os indivíduos tenham suas experiências marcadas por uma normatividade; e a linguagem, que é um meio simbólico de comunicação, aparece como mecanismo que torna possível o entendimento intersubjetivo. Daí que, para Habermas, "o eu se constituí num sistema de limites, no qual a subjetividade da natureza interna se delimita frente à objetividade de uma natureza externa perceptível, frente à normatividade da sociedade e frente à intersubjetividade da linguagem. No todo o qual o eu não somente se sabe como subetividade, mas também como instancia que na linguagem e na interação há transcendido por sua vez e sempre os limites da subjetividade. Pois o eu se identifica consigo mesmo na distinção entre o meramente subjetivo e o não subjetivo". Ou ainda mais brevemente: "A subjetividade se mantem mediante fronteiras frente a natureza externa experimentada em termos objetivos, frente ao plexo da vida social que pretende normatividade e frente à linguagem que establece a intersubjetivdade" (HABERMAS, 1989, pp. 167-168).

À conclusão prévia de que o sujeito só se forma num processo de enfrentamento entre o eu e a realidade circundante, segue-se uma outra segunda a qual o eu e o sistema de distinções em que se constitui surgem cooriginariamente de um único processo evolutivo. Já tratamos das distinções que se expressam na diferenciação das pretensões de validez vinculadas aos atos de fala constatativos, regulativos e representativos, cabendo aqui apenas reforçar a idéia de que a ontogênese do eu representa um complexo processo evolutivo de demarcação de si mesmo em face do outro e de sua integração com 
as estruturas universais de pensamento, linguagem e ação. Assim, o sujeito competente é aquele que resguarda a sua subjetividade, diferencia o uso das competências cognitiva, lingüística e interativa, e é capaz de formular intencionalmente suas expressões, bem como justificá-las. O desenvolvimento da identidade do eu, afirma Habermas, "significa ontogénesis de esa capacidad", lembrando que "la psicología evolutiva, tanto la cognitivista como la psicoanalítica, han reunido evidencias que apoyan la hipótesis de que el desarrollo del yo se efectúa en cuatro etapas que puedem caracterizarse, a su vez, mediante los conceptos de decentración y de deslinde del yo"( (HABERMAS, 1989, p. 170). Em um outro contexto, nosso autor dirá que o desenvolvimento do eu pode ser distinguido em quatro etapas que "se caracterizan no por nuevos contenidos, sino por niveles de la capacidad de aprendizaje que pueden describirse en términos estructurales" (HABERMAS, 1987, p. 101). De modo esquemático, Habermas distingue estes quatro estágios da seguinte forma: o simbiótico, o egocêntrico, o sociocêntrico-objetivista e o universalista. Na fase simbiótica, a distinção entre o eu e seu entorno ainda não é clara, não havendo uma consciência do limite entre o eu corporal e as coisas que o rodeiam. "A simbiose entre a criança, a pessoa de referência e o ambiente é tão estreita que, stricto sensu, não tem sentido falar de delimitação da subjetividade" ((HABERMAS, 1990, 16). No estágio egocêntrico, o eu já consegue delimitar o plano físico de seu corpo e os objetos que o rodeiam, não distinguindo todavia entre relação cognitiva e social; por ter seu horizonte de sentido orientado pela perspectiva de seu corpo, ele mantém um modo egocêntrico de relacionamento com os âmbitos da natureza e da sociedade. $\mathrm{Na}$ fase sociocêntrico-objetivista, o processo de amadurecimento vai se tornando mais nítido quando o eu passa a diferenciar entre o uso cognitivo, quando sua relação com a natureza torna-se objetivante, e o uso lingüístico, com o domínio diferenciado dos atos de fala; além disto, o modo interativo de se relacionar com as pessoas, que passa a moldar suas relações sociais em conexões de complementaridade, vai além das exigências caprichosas do imediatismo que, até então, não reconhecia o convívio social como entrelaçamento de egos. No estágio universalista, os processos de diferenciação e de aperfeiçoamento no uso das competências são marcados pela aquisição da competência reflexiva do eu, portanto por seu distanciamento do dogmatismo, originando "la capacidad de participar en discursos y de pensar en términos hipotéticos" (HABERMAS, 1989, p. 171): em relação à natureza, o eu refere-se a ela de modo explicativo e hipotético, superando uma compreensão imediata e não-reflexiva; no que diz respeito à interação, neste estágio o eu liberta-se do dogmatismo normativo, deixando de aceitar ingenuamente os conteúdos interativos e passando a considerá-los como convenções. Em termos gerais, portanto, o desenvolvimento 
da identidade pode ser entendido como um processo que leva ao descentramento de uma compreensão de mundo marcada inicialmente pela perspectiva do egocentrismo (HABERMAS, 1987, p. 102). Habermas considera a aquisição da competência interativa, a capacidade de tomar parte em interações cada vez mais complexas, como o núcleo da formação da identidade, além de ser a dimensão do desenvolvimento do eu mais diretamente relevante para a teoria da ação social e constituir a base do desenvolvimento da consciência moral.

Habermas propugna também uma espécie de homologia entre ontogênese e filogênese, de maneira que o processo de desenvolvimento do eu contribuiria para o processo de evolução das instituições e dos sistemas sociais, segundo uma lógica de racionalização das imagens de mundo. A racionalidade das imagens de mundo pode ser avaliada, de acordo com a pragmática universal, na dimensão de seu caráter "fechado" ou "aberto", observando-se as mudanças sistemáticas das estruturas das imagens de mundo, seja por fatores externos, seja por fatores internos derivados de um incremento do saber. Assim, "los procesos de aprendizaje tienen que explicarse a su vez por medio de mecanismos empíricos; pero al propio tiempo están concebidos como soluciones de problemas, de modo que tienen que resultar accesibles a una evaluación sistemática en función de condiciones internas de validez. La posición universalista obliga a aceptar, a lo menos in nuce, la hipótesis evolutiva de que la racionalización de las imágenes del mundo se cumple a través de procesos de aprendizaje" ((HABERMAS, 1987, p. 99-100). Enfatizando que tal hipótese não implica numa filosofia objetivista da história, dada a distinção clara entre os aspectos lógico e dinâmico da evolução, Habermas considera que a compreensão das mudanças históricas entre as diversas configurações dos sistemas de interpretações como um processo de aprendizagem requer "un análisis formal de nexos de sentido que permita entender la sucesión empírica de imágenes del mundo como una secuencia de pasos de aprendizaje, reconstruible desde la perspectiva del participante, como si éste mismo la hubiera recorrido, y abierta a la comprobación intersubjetiva"( (HABERMAS, 1987, p. 100). Sob o ponto de vista do desenvolvimento de conceitos formais de mundo, Habermas considera a evolução das imagens de mundo como um processo de aprendizagem passível de reconstrução, caracterizado por mutações nos sistemas de categorias da mentalidade mítica, do pensamento metafísico e religioso e da interpretação moderna do mundo. Nesta linha de pensamento, Habermas se vale da sociologia da religião de Max Weber e da psicologia genética de Jean Piaget, com as quais pode conjugar as dimensões filogenética e ontogenética do processo de racionalização: assim como é possível distinguir as etapas do desenvolvimento cognitivo, que se caracterizam 
não por novos conteúdos, mas por níveis de capacidade de aprendizagem que podem ser descritos em termos estruturais, é possível tratar de maneira similar a emergência de novas estruturas das imagens de mundo. "La teoría de Piaget no sólo puede sernos útil para la distinción entre aprendizaje de estructuras y aprendizaje de contenidos, sino también para la conceptuación de un desarrollo que se extiende a las imágenes del mundo en su integridad, esto es, que abarca simultáneamente las distintas dimensiones de la compreensión del mundo" (HABERMAS, 1987, p. 101-102). No plano cognitivo, o progresso ocorre com a desvalorização dos potenciais de explicação e justificação das interpretações de mundo em razão do aperfeiçoamento da aprendizagem nas diversas dimensões do pensamento objetivante, das idéias prático-morais e das capacidades de expressão estética. É importante perceber, pois, que não são tanto os conteúdos que se esvaziam de sua capacidade de convencimento, e sim o tipo de razão que lhes serve de sustentáculo.

\section{Por Uma História Social Pós-Metafísica}

Como temos visto até aqui, Habermas oferece um projeto crítico-teórico unificado que integra elementos de outras tradições teóricas. Até a publicação da monumental Teoria do Agir Comunicativo, em 1981, seu programa de pesquisa tinha um caráter eminentemente exploratório, razão pela qual Thomas McCarthy advertia que "no debe interpretarse como producto acabado lo que por el momento no es más que una tentativa en curso de clarificar categorías y supuestos básicos"i. Não obstante a heterogeneidade das perspectivas adotadas, os escritos da década de setenta promovem a integração dos conceitos básicos da teoria habermasiana da comunicação. Neste sentido, a obra "Para a Reconstrução do Materialismo Histórico", de 1976, representa um marco na integração dos diversos elementos positivos daquelas análises exploratórias, através de uma teoria da evolução social inspirada numa releitura do marxismo. Habermas dá o nome de "reconstrução" ao procedimento pelo qual "uma teoria é desmontada e recomposta de modo novo, a fim de melhor atingir a meta que ela própria se fixou" (HABERMAS, 1990, 11), reconhecendo que o potencial de estímulo do materialismo histórico não estava ainda esgotado. A seu juízo, a teoria do agir comunicativo pode esclarecer os fundamentos necessários para uma teoria da evolução no exame crítico das categorias centrais do marxismo, tanto de seus dois conceitos de base - o "trabalho social" e a "história da espécie" - quanto de suas duas suposições fundamentais - o teorema da "superestrutura" e a dialética entre "forças produtivas e relações de produção". 
Habermas classifica o materialismo histórico de Marx e Engels como uma teoria da evolução social. Para ele, mesmo que o pensamento marxiano não compartilhe diretamente com essa leitura, ao menos é sabido que suas considerações teóricas se desenvolvem com o interesse de esclarecer 0 processo de desenvolvimento da sociedade capitalista moderna. Na realidade, Habermas encontra não apenas no materialismo histórico, mas também em teorias mais recentes, uma tentativa de se explicar o desenvolvimento social. Assim, ao considerar a história do desenvolvimento da humanidade ${ }^{i i}$, Habermas o faz com um propósito reconstrutivo, analítico e crítico dos pressupostos fundamentais encontrados em diversas teorias do desenvolvimento, seja a de Marx e Engels, seja ainda as de Freud, Chomsky, Piaget e Mead, entre outros. Esta investida visa a construção de um conceito mais amplo de razão, que permita considerar integralmente a prática cotidiana dos indivíduos que trabalham e interagem na reprodução do gênero. No tocante à reconstrução do materialismo histórico, em particular, ainda que se continue considerando a cultura um fenômeno superestrutural, ela é avaliada agora como preeminente na passagem que uma sociedade qualquer realiza para novos níveis de desenvolvimento. Daí que, segundo Araújo, "a reconstrução do materialismo histórico, na qual Habermas retoma com novas bases o privilégio do paradigma da comunicação sobre o paradigma da produção, é o ponto de partida de sua teoria evolucionária"iii. Marx provocou uma reviravolta empírica das categorias sociais e antropológicas da filosofia burguesa, transformando as "condições historicamente existentes", nas quais os homens se realizam, no núcleo de sua investigação. Para isso, seu recurso teórico foi a dialética hegeliana, desta feita referendada nos contextos concretos do modo de reprodução da vida humana, de tal modo que o trabalho (Arbeit) tornou-se a categoria fundamental do processo histórico-social. Habermas, por seu turno, entende que 0 desenvolvimento social, nestes termos, se faz a partir da lógica do agir instrumental e estratégico, antepondo a Marx a dimensão do agir comunicativo como o aspecto central da evolução social. Segundo nosso filósofo, através dele é possível encontrar os mecanismos fundamentais de aprendizagem que possibilitam formas mais incrementadas de integração social, os quais, por sua vez, provocam novas relações de produção, pois são estes mecanismos que permitem o emprego social de novas forças produtivas. Com isso, Habermas evita uma apropriação objetivista da filosofia da história de Hegel e de Marx, bem como de outras tradições teóricas que não levaram em conta a necessidade de correção de seus próprios conteúdos normativos. O materialismo histórico pode ser reconstruído, no seu entender, a partir de considerações interdisciplinares que oferecem uma compreensão mais detalhada e precisa do desenvolvimento social. 


\section{Trabalho e Comunicação. A Dinâmica Social}

Para Marx, o "trabalho socialmente organizado" (Gesellschaftlich organisierte Arbeit) representa a forma específica pelo qual os seres humanos reproduzem a sua vida, à diferença dos outros animais. Habermas explica esta noção a partir de três regras de ação: a instrumental, a estratégica e a comunicativa. As atividades instrumentais de transformação e de reconversão material da natureza externa são coordenadas segundo as regras estratégicas para a determinação dos fins sociais da produção. Como a finalidade da produção é o consumo, o mecanismo de distribuição da produção social seguirá regras interativas - já que ela se baseia em expectativas de reciprocidade, a saber, em normas sociais. Com o esclarecimento dessas orientações de ação, pode-se entender então que a economia é um sistema que organiza e regula toda a produção e circulação, o que permite a Marx concluir que o desenvolvimento humano pode ser medido pelas diversas formas econômicas que a reprodução da vida pode assumir. No entanto, Habermas encontra evidências nas ciências antropológicas que o levam a apontar a debilidade da teoria da reprodução da existência humana de Marx: a reflexão marxiana se fundamenta exclusivamente no horizonte da razão instrumental. $\mathrm{O}$ curso que levou o desenvolvimento do primata antropóide ao homo sapiens teve inicialmente um suposto antepassado comum ao chipanzé. A linhagem hominídea, à qual pertence a espécie humana, seguiu uma articulação evolutiva (hominização) segundo mecanismos de desenvolvimento cultural e orgânico. Para Habermas, "por um lado, nesse longo período da antropogênese, alteramse - com base numa longa série de mutações - o tamanho do cérebro e importantes características morfológicas; por outro lado, os ambientes de onde parte o impulso seletivo trazem a marca não mais apenas da ecologia natural, mas já das realizações ativas de adaptação das hordas de homínidas dedicadas à caça" (HABERMAS, 1990, 114). Habermas propõe, então, a existência de dois tipos de evolução: a dos mecanismos natural e social. $\mathrm{Na}$ evolução dos mecanismos naturais, a forma mista orgânico-cultural do processo de hominização é interrompida com o surgimento do homo sapiens, de natureza biologicamente fixa. A partir daí, a espécie homo sapiens deflagra somente o desenvolvimento dos patrimônios sócio-hereditários (interações sociais constituídas em formas de organização coletiva) guiados exclusivamente por mecanismos sociais de aprendizagem. Por isso, diz Habermas, que "tãosomente no limiar que introduz ao homo sapiens é que essa forma mista orgânico-cultural da evolução cede lugar a uma evolução exclusivamente social. 
Cessa o mecanismo natural de evolução. Não nascem mais novas espécies" (HABERMAS, 1990, 114). Ainda sobre a construção histórico-materialista da noção de trabalho social, agora à luz das investigações antropológicas ulteriores, nosso autor conclui que o pensamento marxista privilegia somente o processo evolutivo que cinde a linhagem dos hominídeos e as dos macacos antropóides. Segundo ele, a fabricação de meios de produção, a organização social do trabalho e a distribuição do montante produzido, são apenas condições que formam as situações econômicas de reprodução da vida. Partir exclusivamente destas categorias impede a captação dos mecanismos integrais de reprodução da vida dos seres humanos. Para Habermas, o homo sapiens supera a estrutura social baseada na ordem hierárquica unidimensional - modelo de organização social que privilegia os ditames da esfera de ação instrumental.

Nas sociedades humanas, o modo de produção socialmente organizado provocou necessariamente formas inovadoras de integração social. Enquanto as sociedades hominídeas se baseavam na arcaica ordem unidimensional de status, as sociedades humanas organizam a produção, o trabalho e a distribuição de bens e serviços segundo normas sociais, as quais estão baseadas em estruturas familiares e num sistema lingüístico integralmente constituído. Assim, Habermas considera que as sociedades humanas substituíram os sistemas de integração baseados no status animal por um sistema de normas e papéis sociais. Em suas palavras, "somente nas estruturas de trabalho e linguagem completaram-se os desenvolvimentos que levaram à forma de reprodução da vida especificamente humana e, com isso, à condição que serve como ponto de partida da evolução social. Trabalho e linguagem são anteriores ao homem e à sociedade"(HABERMAS, 1990, 118). Os resultados conclusivos dos estudos antropológicos poderiam significar para o materialismo histórico as seguintes implicações: 1) o conceito de trabalho social é fundamental para entender as evoluções da organização social do trabalho e da distribuição como algo anterior ao desenvolvimento lingüístico e ao desenvolvimento dos sistemas de papéis sociais; 2) mesmo que o conceito de trabalho social tenha uma proeminência na teoria da evolução hominídea, só é possível entender especificamente a evolução das formas de vida humana se se unir o conceito de trabalho social ao princípio familiar de organização; 3) as estruturas do agir segundo os papéis sociais representam novas etapas de desenvolvimento que não podem mais ser reduzidas às regras de ação instrumental ou estratégica; 4) a produção (trabalho) e a socialização (interação) são de igual importância para a reprodução da espécie humana, estando governadas agora pela estrutura familiar como instância reguladora e integradora da natureza interna e externa. A forma específica de reprodução da vida humana é constituída pela evolução do trabalho social e pelo desenvolvimento da linguagem, de tal forma que só se 
pode falar de existência humana quando se leva em consideração a conjunção dos âmbitos da ação instrumental e da ação comunicativa.

\section{A lógica do Desenvolvimento Social}

A partir dessas conclusões prévias, Habermas analisa o conceito marxista de "história da espécie" (Gattungsgeschichte) associado ao já examinado conceito de trabalho social. Em Marx, o trabalho social é o meio pelo qual os homens conservam suas vidas. Deste modo, a experiência integral da sociedade (a formação da identidade dos indivíduos e o processo de transformação social) é pensada como criação humana a partir de suas relações materiais de vida (HABERMAS, 1990, 119). Segundo Habermas, Marx aplicava o "modo de produção" como chave para a reconstrução da história da vida humana, assentado em termos de "forças produtivas" e de "relações de produção". Esta reconstrução histórico-materialista da espécie, preconizada por Marx, ordenava logicamente a evolução humana em estágios conexos "como uma sucessão discreta de modos de produção" (HABERMAS, 1990, 119). Um modo de produção se caracteriza por determinados estágios de desenvolvimento das forças produtivasiv e das relações de produçãov. Para Habermas, "o materialismo histórico parte do fato de que as forças produtivas e as relações de produção não variam independentemente umas das outras, mas formam estruturas que: a) se correspondem reciprocamente; b) produzem somente um número finito de graus de desenvolvimento estruturalmente análogos; de modo que: c) o resultado é uma série de modos de produção que devem ser ordenados segundo uma lógica de desenvolvimento" (HABERMAS, 1990, 120). Deste modo, a versão ortodoxa do marxismo distingue cinco modos de produção - comunismo primitivo, antigo, feudal, capitalista e socialista -, acrescentando-se o modo de produção asiático com o intuito de situar as características próprias do Oriente Antigo e da América pré-colombiana. Estes seis modos de produção deveriam designar os graus de evolução social sobre os quais se pode analisar cada estrutura econômica em particular.

Segundo Habermas, a história da espécie reconstruída pelo materialismo histórico contém as mesmas aporias presentes nas filosofias da história dos Séculos XVIII e XIX, particularmente a consideração do curso da história como algo "unilinear, necessário, ininterrupto e ascendente de um macrossujeito" (HABERMAS, 1990, 120). Na versão habermasiana da teoria da evolução, o desenvolvimento social não é fixado em termos de um "sujeito histórico universal". Para Habermas, a evolução deve ser reconstruída a partir da ação integrada entre sujeito e sociedade, segundo estruturas que são substituídas por 
outras mais abrangentes conforme as várias dimensões da racionalização. A seu ver, "mesmo que a evolução social devesse indicar a direção de uma aquisição consciente de influência dos indivíduos associados sobre o processo de sua própria evolução, disso não resultaria de modo algum a constituição de sujeitos de formato gigante, mas - quando muito - elementos comuns intersubjetivos autoproduzidos e de nível mais elevado" (HABERMAS, 1990, p. 121). Ao passo que Marx sustentava a idéia de que o processo evolutivo se apoiava no desenvolvimento unilinear das forças produtivas e das relações de produção, Habermas sustenta, em sua versão revisada do materialismo histórico, que os critérios do progresso histórico devem ser justificados com base nas várias dimensões da racionalização. Ele parte da distinção entre a lógica do desenvolvimento e a dinâmica do desenvolvimento: enquanto a dinâmica referese aos processos condicionados de evolução dos substratos empíricos, a lógica representa o modelo racionalmente reconstruível de uma hierarquia de estruturas empíricas cada vez mais abrangentes. Por essa razão, Araújo afirma corretamente que a teoria habermasiana da evoluçãovi, embora postule estruturas universais invariantes, não negligencia a variação dos mecanismos empíricos, dispensando-se igualmente de tecer prognósticos para o futuro. A nova orientação dada por Habermas ao conceito de história da espécie parte da idéia de que os aspectos universais da evolução social e os princípios de ordenação da lógica do desenvolvimento devem ser formulados com maior abstração a fim de se evitar prescrições histórico-culturais. Neste sentido, McCarthyvii afirma que uma teoria da evolução construída a partir de referências mais abstratas permite que as especificidades sejam reconstruídas a partir de mecanismos existentes, das condições e das circunstâncias iniciais de uma sociedade qualquer, bem como de outros marcos empíricos. Portanto, Habermas propõe uma combinação dos planos "genético-estrutural" e "históricoempírico". Metodologicamente, esta ponderação busca satisfazer a adequação entre a estruturação lógico-evolutiva da teoria com a dimensão contextual (empírica) das diversidades sociais - condição sine qua non para uma teoria pós-metafísica da evolução.

Ainda sobre o conceito de evolução social, Habermas articula as etapas de formação social a partir do princípio fundamental de organização social. Por "princípio de organização" (Organisationsprinzip) Habermas entende, de acordo com uma passagem que reproduzimos na íntegra, "as inovações que se tornam possíveis através de graus de aprendizagem reconstruíveis segundo uma lógica de desenvolvimento, e que institucionalizam um nível de aprendizado da sociedade que se apresenta como novo em cada oportunidade. O princípio de organização de uma sociedade delimita margens de possibilidade; estabelece, em particular, dentro de que estruturas são possíveis transformações do sistema 
institucional, e em que proporção podem ser socialmente utilizadas as capacidades disponíveis de forças produtivas, ou em que proporção pode ser estimulado desenvolvimento de novas forças produtivas. Por isso, ele estabelece também até que ponto podem ser ampliadas a complexidade sistêmica e a capacidade de direção e de controle. Um princípio de organização comporta regulamentações tão abstratas que, na formação social que ele define, são admitidos mais de um modo de produção funcionalmente equivalentes. A estrutura econômica de uma determinada sociedade, portanto, deveria ser investigada em dois planos analíticos: inicialmente, nos termos dos modos de produção que nela estabeleceram um vínculo concreto; e, depois, nos termos da formação social à qual pertence o modo de produção dominante em cada oportunidade"( HABERMAS, 1990, 134). O que é fundamental nesta passagem é o fato de demonstrar que pensar o desenvolvimento histórico com base no conceito de princípio de organização social significa, em Habermas, entender a evolução social como um processo de aprendizagem. Daí a importante conclusão de McCarthy: "la idea rectora es que la evolución social puede ser entendida como un proceso de aprendizaje, no en el sentido de la psicología behaviourista - que, a juicio de Habermas, no es lo suficientemente compleja para captar otra cosa que mecanismos de aprendizaje periféricos -, sino en el sentido de la psicología evolutiva cognitiva. Para este planteamiento es central la noción de lógica evolutiva, la cual incluye una distinción entre niveles de aprendizaje, que pueden caracterizarse en términos formales, y los procesos de aprendizaje que son posibles en cada uno de esos niveles"viii.

As características fundamentais de integração social são apresentadas numa lógica evolutiva somente quando os incrementos instrumentais e sócioculturais que acontecem são descritos num processo de aprendizagem social circunscrito nas possibilidades existentes nos mecanismos produtivos e nas normas existentes. Marx entendeu o processo de superação das crises sociais a partir da dialética entre forças produtivas e relações de podução. Ora, seguindo uma tal orientação teórica nos deparamos com o entendimento de que as técnicas produtivas fundamentam autonomamente as soluções e 0 gerenciamento das crises geradas no processo civilizatório. No entender de Habermas, entretanto, as "melhorias" representam um processo de aperfeiçoamento de instituições contextualmente defasadas na coordenação de problemas sistêmicos. Afirma ele, neste sentido, que "um mecanismo endógeno de aprendizagem leva à acumulação de um potencial cognoscitivo que pode ser utilizado para a solução dos problemas sistêmicos geradores de crise"( HABERMAS, 1990, 128). Araújo, por seu turno, diz que o desenvolvimento das forças produtivas "representa - no máximo - um mecanismo de criação de novos problemas e não um mecanismo produtor de reais inovações evolutivas. $O$ 
surgimento de princípios sociais de organização fica, então, vinculado a processos evolutivos de aprendizagem"ix. Assim, a resposta analítica proposta por Habermas sobre a questão fundamental do processo de desenvolvimento das sociedades parte do crescimento endógeno do saber como condição necessária para que uma sociedade produza novas formas de integração social.

Enquanto o marxismo tradicional entendia que a evolução social resultava do incremento das forças produtivas, Habermas entende que a espécie humana não aprende apenas na dimensão do saber técnico-produtivo, mas também na da consciência prático-moral. Em posição crítica ao teorema da superestrutura de Marx, Habermas acredita que a esfera comunicativa se desenvolve em reação às mudanças na esfera do agir estratégico e instrumental, seguindo todavia uma lógica própriax. Dito assim, somente quando surgem novas formas institucionais de integração social é que se abrem as possibilidades de se considerar os problemas sistêmicos não resolvidos. Estas novas formas institucionais surgem como resposta ao potencial cognitivo acumulado, que tardiamente resulta no aumento das forças produtivas: o potencial cognitivo acumulado já não se coaduna com os mecanismos deficitários de integração social e só pode ser implementado se surgirem novas formas de integração social. Como afirma Araújo, "o eixo da teoria habermasiana da evolução social é constituído pela idéia segundo a qual os processos ontogenéticos de aprendizagem representam um estoque, por assim dizer, da evolução filogenética, de tal modo que, se a capacidade de direção estruturalmente limitada dos sistemas sociais (que são distintos dos sistemas de personalidade) é transbordada por problemas inevitáveis, toda sociedade pode recorrer, em certas circunstâncias, às capacidades de excedente do aprendizado individual de seus membros ou ainda às capacidades coletivas de aprendizado (interpretação de mundo) a fim de utilizá-las na institucionalização de novos níveis de aprendizagem"xi. Nestes termos, a lógica evolutiva no materialismo renovado de Habermas procurará reconstruir, em níveis de aprendizagem, os respectivos princípios de organização possíveis em cada um deles - enquanto estruturas de consciência coletivamente compartilhadas, encarnadas em instituições de integração social.

\section{Conclusão}

A teoria da evolução de Habermas tem como base a psicologia cognitiva de Jean Piaget. Nos estudos sobre o desenvolvimento da competência da identidade (desenvolvimento do eu), já apresentados anteriormente, pudemos acompanhar o modo como as competências cognitiva e interativa dos indivíduos 
são resultados de processos de amadurecimento e de aprendizagem. Elas foram distribuídas de tal modo que pudessem explicitar, em estágios ordenados, as seqüências hierárquicas e invariantes da capacidade individual de aprendizado. De uma maneira análoga, para Habermas, as modificações sistêmicas podem seguir uma sucessão hierárquica de etapas mais complexas e compreensivas que as anteriores - somente, porém, enquanto sistema suscetível de conservação e transmissão de inovações do potencial cognitivo dos indivíduos ${ }^{\text {xii. }}$.

A evolução social parte de processos de aprendizagem que extravasam os limites estruturais dos sistemas de integração que lhes são atuais. Com isso, distingue-se a solução dos problemas de direção, que levam ao avanço evolutivo, dos mecanismos de aprendizagem subjacentes, que explicam por que uma determinada sociedade supera ou não seus problemas evolutivos. Mas tal paralelismo rejeita qualquer relação direta entre o desenvolvimento individual e a evolução das imagens de mundo. Habermas adverte, com efeito, que a evolução social difere do processo de desenvolvimento cognitivo dos indivíduos, na medida em que o aprendizado individual é dependente de processos biológicos e a evolução social se realiza exclusivamente no plano sócio-cultural, sendo, portanto, transmitida como parte de uma tradição.

Ao analisar o processo ontogenético como estoque do processo filogenético, Habermas sugere uma homologia restrita que respeite a especificidade das estruturas de consciência e das estruturas de integração social. Consciente do distanciamento entre as competências individuais e as articulações do sistema social ${ }^{1}$, a homologia proposta por Habermas explica tãosomente o processo de aprendizagem de que ambas são passíveis, tornando possível um descentramento progressivo (racionalização) das imagens de mundo. Portanto, podemos concluir que a evolução social é o processo pelo qual a racionalização das imagens de mundo se encarna em novas instituições de integração social, possibilitando a implementação de inovações tecnológicas e o aumento da comlexificação social. A homologia trata de compreender 0 desenvolvimento - filogênico ou ontogênico - como um processo de descentramento, tanto das imagens de mundo quanto dos sistemas de interpretação, com a consequente delimitação formal dos conceitos de mundo (subjetivo, objetivo e social).

\section{Referências}

\footnotetext{
1 Quanto a essas limitações, diz Habermas que "não devemos deduzir da ontogênese conclusões apressadas para os níveis de desenvolvimento das sociedades. Os processos de aprendizagem na evolução social não podem ser atribuídos nem apenas à sociedade, nem somente aos indivíduos" (HABERMAS, 1990, p. 135).
} 
ARAÚJO, Luiz Bernardo Leite. Religião e modernidade em Habermas. São Paulo: Ed. Loyola, 1996.

HABERMAS, Jürgen.. Teoria de la acción comunicativa I. Racionalidad de la accíon y racionalización social. Madrid: Taurus, 1987.

HABERMAS, Jürgen. Teoría de la acción comunitativa: complementos y estudios previos. Madrid: Catedra, 1989.

HABERMAS, Jürgen. Para a reconstrução do materialismo histórico. São Paulo: Ed. Brasiliense, 1990 (2a edição).

KESSELRING, Thomas. "Jean Piaget: um diálogo", in: Jürgen Habermas: 70 anos. Revista Tempo Brasileiro, n. 70, Julho-Setembro (1999): 75-88, particularmente o quadro apresentado na página 75 .

McCARTHY, T. La teoría crítica de Jürgen Habermas, Madrid: Tecnos, 1992.

SOUZA, Jessé. Patologias da modernidade: um diálogo entre Habermas e Weber. São Paulo: Annablume, 1997.

\footnotetext{
i McCARTHY, T. La teoría crítica de Jürgen Habermas, op. cit., p. 273.

ii Para Souza, a reconstrução do materialismo histórico complementa o papel da pragmática universal na teoria da comunicação de Habermas. Nos seus dizeres, "temos uma teoria da evolução, a qual confere o caráter 'diacrônico' à teoria da ação comunicativa, em contraposição ao caráter 'sincrônico' da pragmática universal” (cf. SOUZA, Jessé. Patologias da modernidade: um diálogo entre Habermas e Weber, op. cit., p. 18-19.

iii ARAÚJO, Luiz B. L. Religião e modernidade em Habermas, op. cit., p. 40.

iv As forças produtivas constituem-se na força de trabalho, no conhecimento técnico para a intensificação da produção e na organização social das mobilizações e das qualificações das forças de trabalho. No plano histórico-materialista de Marx, as forças produtivas determinam o grau de dominação possível sobre os processos naturais. Sobre isto, cf. HABERMAS, 1990, p. 119.

v Segundo McCarthy, as relações de produção "son las instituciones y los mecanismos sociales que determinan cómo puede combinarse la fuerza de trabajo con los medios de producción disponibles, en un nivel dado de las fuerzas productivas" (McCARTHY, T. La teoría crítica de Jürgen Habermas, op. cit., p. 279). Assim, o controle de acesso aos meios produtivos regula também, mesmo que indiretamente, a distribuição da riqueza socialmente produzida. A relação de produção manifesta a distribuição social do poder, ela orienta a estrutura dos interesses subsistente numa sociedade.

vi Cf. ARAÚJO, Luiz B. L. Religião e Modernidade em Habermas, op. cit. p. 44.

vii Cf. McCARTHY, T. La teoría crítica de Jürgen Habermas, op. cit., p.282.
} 
viii McCARTHY, T. La teoría crítica de Jürgen Habermas, op. cit., p. 287.

ix ARAÚJO, Luiz B. L. Religião e Modernidade em Habermas, op. cit., p. 47.

× Sobre isso e o que se segue, cf. HABERMAS, 1990, p. 128.

xi ARAÚJJO, Luiz B. L. Religião e Modernidade em Habermas, op. cit., p. 45.

xii Sobre esse assunto, cf. McCARTHY, T. La teoría crítica de Jürgen Habermas, op. cit., p. 296. 